\title{
Two novel nonsense mutations in GALNT3 gene are responsible for familial tumoral calcinosis
}

\author{
Anna Maria Barbieri · Marcello Filopanti · \\ Guido Bua $\cdot$ Paolo Beck-Peccoz
}

Received: 22 December 2006/ Accepted: 8 February 2007/Published online: 10 March 2007

(C) The Japan Society of Human Genetics and Springer 2007

\begin{abstract}
Ectopic periarticular calcifications associated with elevated levels of serum phosphate represent the principal clinical features of hyperphosphatemic familial tumoral calcinosis (HFTC), a rare autosomal recessive metabolic disorder. The disease can be caused by recessive mutations in at least two different genes: GalNAc transferase 3 (GALNT3), encoding a glycosyltransferase that initiates mucin-type $O$-glycosylation, and fibroblast growth factor 23 (FGF23), which encodes a regulator of phosphate circulating levels. In the current study, we performed mutation analyses of the GALNT3 gene in a subject with HFTC and in his relatives. Sequence analyses revealed that the proband was a compound heterozygote for two novel nonsense mutations in exon $4(\mathrm{Y} 322 \mathrm{X})$ and in exon 7 (Q481X). Cosegregation of the mutations with the disease within the family was confirmed by polymerase chain reaction restriction fragment length polymorphism (PCRRFLP) analysis. This is the first report describing the simultaneous presence of two different stop codons in the coding sequence of the GALNT3 gene.
\end{abstract}

\section{Keywords Calcinosis - GALNT3 - FGF23 - Mutation · Phosphate}

\section{Introduction}

Familial tumoral calcinosis (FTC) with hyperphosphatemia (HFTC; MIM \#211900) is a rare autosomal recessive metabolic disorder characterized by the progressive deposition of calcium phosphate crystals in the skin and subcutaneous tissues. These calcified masses look like irregular tumors, which usually develop in a periarticular position, causing pain and often necessitating surgical excision. Affected individuals have hyperphosphatemia due to increased renotubular reabsorption of phosphate and show elevated or inappropriately normal levels of serum 1,25-dihydroxyvitamin D (calcitriol), whereas calcium and parathyroid hormone (PTH) levels are normal (Prince et al. 1982; Metzker et al. 1988; Slavin et al. 1993). In these patients, elevated calcitriol levels are likely to lead to increased intestinal phosphate absorption, thus contributing to hyperphosphatemia. Recently, biallelic mutations in the UDP- $N$-acetyl- $\alpha$-D-galactosamine/ polypeptide $N$-acetylgalactosaminyl transferase 3 (GalNAc transferase 3, or GALNT3) gene located on 2q24$2 \mathrm{q} 31$ have been identified in patients with HFTC (Topaz et al. 2004; Ichikawa et al. 2005, 2006; Specktor et al. 2006; Campagnoli et al. 2006; Garringer et al. 2006). GALNT3 belongs to a family of genes that encodes Golgiassociated biosynthetic enzymes involved in the initiation of mucin-type $O$-glycosylation, a posttranslational modification (Bennet et al. 1996; Ten Hagen et al. 2003). The recent identification of a mutation in GALNT3 in families with hyperostosis-hyperphosphatemia syndrome (HHS), a rare autosomal recessive bone disorder that shares some features with HFTC, demonstrated that mutations in GALNT3 cause two distinct syndromes and that HFTC and HHS are allelic disorders (Frishberg et al. 2005). In addition, mutations in the gene encoding for the fibroblast 
growth factor 23 (FGF23), a key regulator of phosphate homeostasis, have been found in families with HFTC (Benet-Pagès et al. 2005; Larsson et al. 2005; Chefetz et al. 2005; Araya et al. 2006). Thus, recessive mutations in at least two different genes, GALNT3 and FGF23, can be the molecular cause of the disorder. In the present study, we performed mutation analysis of the GALNT3 gene in an Italian family with a subject with HFTC and identified two novel nonsense mutations responsible for the disease.

\section{Materials and methods}

Patient and control individuals

Blood samples were collected from the patient, his family, and control subjects after having obtained written and informed consent before their participation in the study, which was approved by the local Hospital Ethical Committee. Routine serum and urinary biochemistry was assessed by standard protocols. The ratio of the renal tubular maximum reabsorption rate of phosphate to the glomerular filtration rate (TmP/GFR) was calculated with the nomogram of Bijvoet (Walton and Bijvoet 1975).

Mutation analysis

Genomic DNA was extracted from whole blood using a Nucleon BACC kit (Amersham Biosciences, Little Chalfont, Buckinghamshire, UK). Primers were designed to amplify all ten GALNT3 coding exons, as well as conserved splice junctions, by standard polymerase chain reaction (PCR) methods. Primer sequences are available on request. PCR products were resolved on a $1 \%$ agarose gel and purified using GFX PCR DNA and Gel Band Purification Kit (Amersham Biosciences). Purified fragments were directly sequenced using the AmpliTaq BigDye terminator kit and the 310 Genetic Analyzer (Perkin Elmer Applied Biosystems, Foster City, CA, USA).

PCR-restriction fragment length polymorphism (RFLP) analysis

Genomic DNA fragments containing nonsense mutations in exons 4 and 7 were amplified by PCR and purified as previously described. Exon 4 PCR products were digested with Bsu36I (New England Biolabs, Beverly, MA, USA), whereas exon 7 PCR products were incubated with TspRI (New England Biolabs). Digested PCR products were resolved by gel electrophoresis.
Measurements of circulating FGF23

Plasma samples were isolated by centrifugation and immediately frozen before biochemical analysis. FGF23 levels in plasma were assessed using a commercially available sandwich enzyme-linked immunosorbent assay (ELISA) (Immutopics, Inc., San Clemente, CA, USA, Cat. \# 60-6000). This kit detects both full-length and Cterminal fragments of FGF23, as the two polyclonal antibodies used for the two-site sandwich were selected against the C-terminal portion of FGF23. ELISA was performed according to the manufacturer's protocol.

\section{Results}

\section{Clinical findings}

The family is Caucasian, and its pedigree is shown in Fig. 1a. Parents of the proband come from two small villages of the north of Sardinia, Italy, and they have no history of consanguinity. The proband is a 40-year-old man and shows the classical manifestations of HFTC. Starting from the first decade of life, he developed massive semicalcific lesions (Fig. 2) and underwent numerous surgeries to remove calcified deposits. From a biochemical point of view, he has hyperphosphatemia $(6.6 \mathrm{mg} / \mathrm{dl}$, normal range $2.5-5.0 \mathrm{mg} / \mathrm{dl})$ and increased levels of calcitriol $(91 \mathrm{pg} / \mathrm{ml}$, normal range $19.9-67 \mathrm{pg} / \mathrm{ml})$. Serum calcium, creatinine, bone alkaline phosphatase, osteocalcin, and PTH levels were normal (Table 1). The fractional tubular reabsorption of phosphate (TRP) was 95\% (normal 82-90\%); TmP/GFR was elevated $(7.7 \mathrm{mg} / \mathrm{dl}$; normal range $2.5-4.2 \mathrm{mg} / \mathrm{dl})$. FGF23 plasma levels were assayed in the patient with a Cterminal assay. This assay recognizes both full-length and C-terminal portion of FGF23, which originates from a cleavage by subtilisin-like proprotein convertase (SPC) between R179 and S180 (Shimada et al. 2002). The assay showed elevated FGF23 levels in the patient (746 RU/ml) compared with normal controls (mean: $35.4 \pm 14.4 \mathrm{RU} / \mathrm{ml}$, with reference range $<150 \mathrm{RU} / \mathrm{ml}$ ), in agreement with previous reports of HFTC patients carrying mutations in GALNT3 (Topaz et al. 2004; Garringer et al. 2006; Ichikawa et al. 2006).

Mutation analysis

Direct sequencing of PCR products of all ten coding exons and conserved splice sites of GALNT3 revealed that the proband (II-2) is a compound heterozygote for two nonsense mutations that have not been previously described. The transversion $\mathrm{T} \rightarrow \mathrm{G}$ at cDNA position 966 determines the substitution of a tyrosine with a stop co- 
a

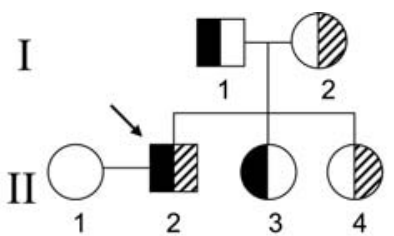

b
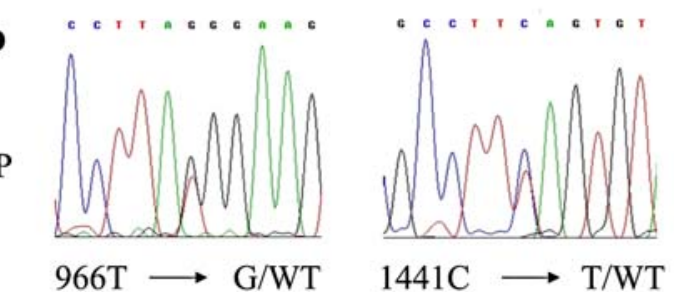

E

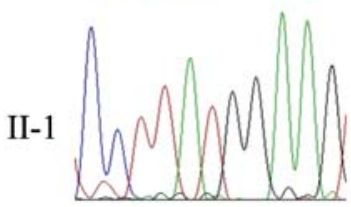

WT/WT

c

$966 \mathrm{~T} \longrightarrow \mathrm{G}$

Bsu36 Digest

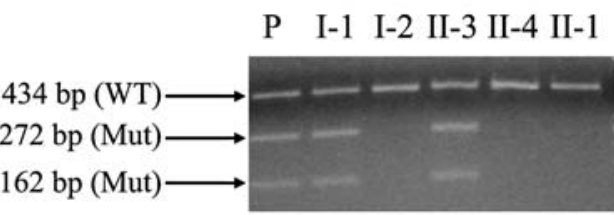

$1441 \mathrm{C} \longrightarrow \mathrm{T}$

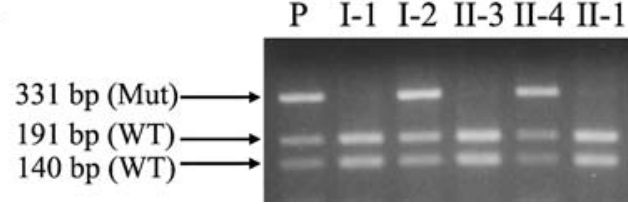

Fig. 1 Family pedigree and mutation analysis. a Pedigree of the studied family. Circles indicate female subjects; squares indicate male subjects. Filled symbol denotes the affected individual; halffilled symbols denote carrier individuals. Black symbols indicate Y322X mutation, symbols with hashed lines indicate Q481X mutation. An arrow indicates the proband. b Sequence analysis of the GALNT3 gene. Direct sequencing revealed that the proband $(P)$ is a compound heterozygote with respect to a $\mathrm{T} \rightarrow \mathrm{G}$ transversion at cDNA position 966 (Y322X) (left upper panel) and a $\mathrm{C} \rightarrow \mathrm{T}$ transition at cDNA position 1441 (Q481X) (right upper panel). The wild-type sequences of exons 4 and 7 are shown in the lower panels. $\mathbf{c}$ Polymerase chain reaction restriction fragment length polymorphism (PCR-RFLP) analysis. The Y322X mutation creates a novel Bsu36I recognition site, and therefore, two additional fragments (272 and $162 \mathrm{bp}$ ) are generated after digestion with the corresponding enzyme. In wild-type individuals, incubation with Bsu36I produces an undigested 434-bp fragment (upper panel). The Q481X mutation disrupts a $T s p R$ I restriction site. Thus, after incubation with $T s p R I$, the mutated allele remains undigested (331 bp), whereas the wild-type allele produces two fragments (191 and $140 \mathrm{bp)}$ (lower panel)

don $(\mathrm{Y} 322 \mathrm{X})$ in exon 4. A second stop codon, which eliminates a glutamine, is generated by the transition $\mathrm{C} \rightarrow \mathrm{T}$ at cDNA position 1441 (Q481X) in exon 7 (Fig. 1b). Proband's father (I-1) and one of his sisters
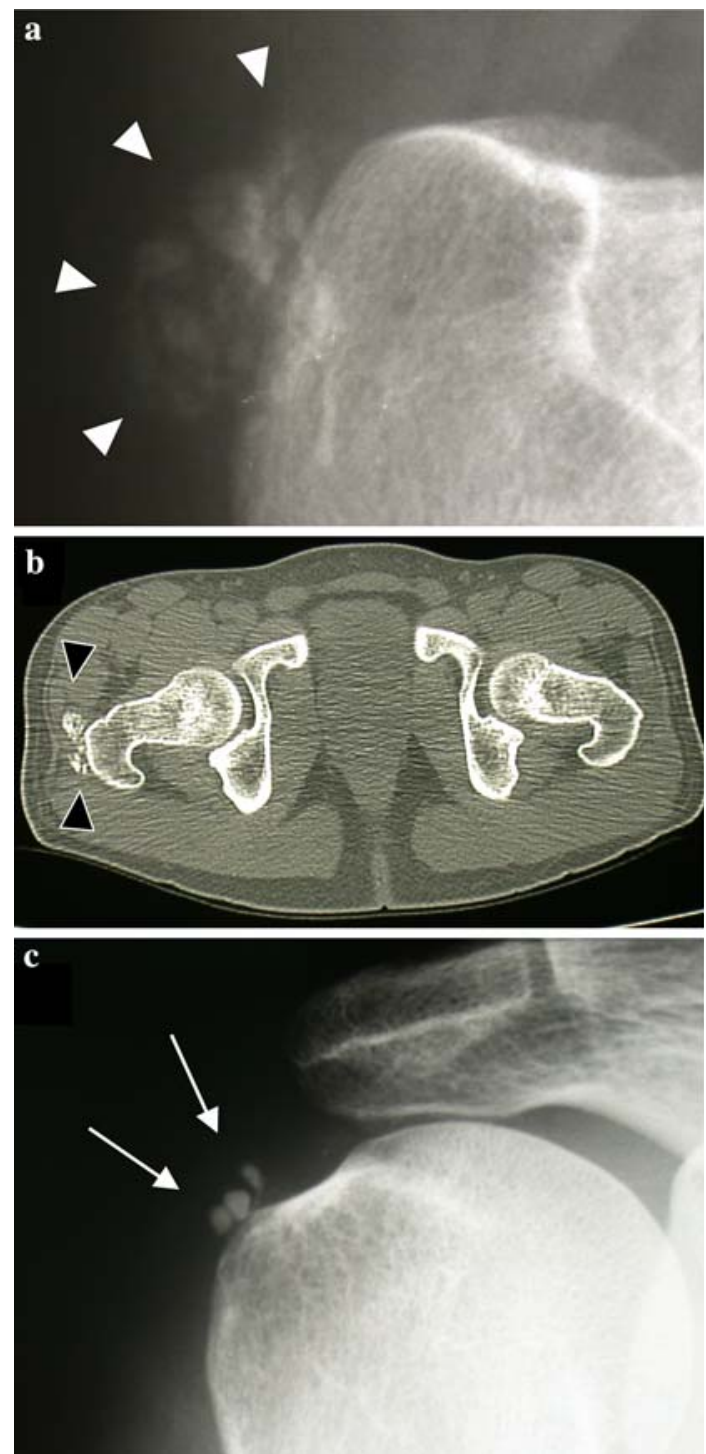

Fig. 2 Clinical and imaging features of the patient. a X-ray showing a calcified mass near the right greater trochanter (arrowheads); a similar lesion was found over the left greater trochanter (data not shown). b Computerized tomography (CT) scan of the pelvis confirmed the presence of the lesion described in a (arrowheads). c Small calcified masses over the head of the right humerus were detected by X-ray examination (arrows)

(II-3) carry the nonsense mutation in exon 4 , whereas his mother (I-2) and the younger sister (II-4) carry the nonsense mutation in exon 7. To confirm cosegregation of the mutations with the disease, PCR-RFLP analysis was performed (Fig. 1c).

\section{Discussion}

In the current study, we report the identification of two novel mutations in the GALNT3 gene in a patient with 
Table 1 Biochemical analysis of the proband

\begin{tabular}{|c|c|c|}
\hline Measurement & Patient & Normal range (SI units) \\
\hline Serum phosphorus & $6.6 \mathrm{mg} / \mathrm{dl}(2.13 \mathrm{mmol} / \mathrm{l})$ & $2.5-5.0 \mathrm{mg} / \mathrm{dl}(0.8-1.6 \mathrm{mmol} / \mathrm{l})$ \\
\hline Serum calcium & $10.1 \mathrm{mg} / \mathrm{dl}(2.53 \mathrm{mmol} / \mathrm{l})$ & $8.5-10.5 \mathrm{mg} / \mathrm{dl}(2.1-2.6 \mathrm{mmol} / \mathrm{l})$ \\
\hline Serum creatinine & $0.88 \mathrm{mg} / \mathrm{dl}(67.1 \mathrm{nmol} / \mathrm{ml})$ & $0.6-1.3 \mathrm{mg} / \mathrm{dl}(46-99 \mathrm{nmol} / \mathrm{ml})$ \\
\hline 24-h urinary calcium & $240 \mathrm{mg} / 24 \mathrm{~h}(6 \mathrm{mmol} / 24 \mathrm{~h})$ & $100-300 \mathrm{mg} / 24 \mathrm{~h}(2.5-7.5 \mathrm{mmol} / 24 \mathrm{~h})$ \\
\hline $\begin{array}{l}\text { 24-h urinary } \\
\text { creatinine }\end{array}$ & $2.22 \mathrm{~g} / 24 \mathrm{~h}(19.5 \mathrm{mmol} / 24 \mathrm{~h})$ & $1.0-2.5 \mathrm{~g} / 24 \mathrm{~h}(8.8-22 \mathrm{mmol} / 24 \mathrm{~h})$ \\
\hline $\begin{array}{l}\text { 1,25-dihydroxyvitamin } \\
\text { D (calcitriol) }\end{array}$ & $91 \mathrm{pg} / \mathrm{ml}(218.4 \mathrm{pmol} / \mathrm{l})$ & $19.9-67 \mathrm{pg} / \mathrm{ml}(48-161 \mathrm{pmol} / \mathrm{l})$ \\
\hline $\begin{array}{l}\text { Intact parathyroid } \\
\text { hormone (PTH) }\end{array}$ & 29 pg/ml (29 ng/l) & $10-65 \mathrm{pg} / \mathrm{ml}(10-65 \mathrm{ng} / \mathrm{l})$ \\
\hline $\begin{array}{l}\text { Bone alkaline } \\
\text { phosphatase }\end{array}$ & $8.6 \mathrm{ng} / \mathrm{ml}(8.6 \mathrm{mg} / \mathrm{l})$ & $0-20 \mathrm{ng} / \mathrm{ml}(0-20 \mathrm{mg} / \mathrm{l})$ \\
\hline Osteocalcin & $7.1 \mathrm{ng} / \mathrm{ml}(7.1 \mathrm{mg} / \mathrm{l})$ & $3.2-12.2 \mathrm{ng} / \mathrm{ml}(3.2-12.2 \mathrm{mg} / \mathrm{l})$ \\
\hline FGF23 (C-Term) & $746 \mathrm{RU} / \mathrm{ml}$ & Mean: $35.4 \pm 14.4 \mathrm{RU} / \mathrm{ml}$ \\
\hline $\begin{array}{l}\text { Tubular maximum } \\
\text { reabsorption rate } \\
\text { of phosphate to } \\
\text { the glomerular } \\
\text { filtration rate } \\
\text { (TmP/GFR) }\end{array}$ & $7.7 \mathrm{mg} / \mathrm{dl}(2.48 \mathrm{mmol} / \mathrm{l})$ & $2.5-4.2 \mathrm{mg} / \mathrm{dl}(0.8-1.36 \mathrm{mmol} / \mathrm{l})$ \\
\hline
\end{tabular}

HFTC. Both mutations are nonsense and cause premature termination of translation of GalNAc transferase 3. This Golgi-associated enzyme catalyzes the initial reaction in $O$ linked oligosaccharide biosynthesis, by transferring a GalNAc ( $N$-acetyl-D-galactosamine) from the sugar donor UDP-GalNAc to the hydroxyl group of a serine or threonine residue on the acceptor protein (Bennet et al. 1996; Ten Hagen et al. 2003). Truncated proteins encoded by Y322X and Q481X mutations lack the ricin B-type lectin domain (residues: 504-630), which binds to GalNAc and contributes to the glycopeptide specificity. In addition, Y322X mutation eliminates the domain B (also called Gal/ GalNAc-T motif, residues: 356-418) that is likely involved in the catalytic reaction and UDP-Gal binding.

The patient shows classical biochemical hallmarks of the disorder, i.e., hyperphosphatemia due to increased phosphate reabsorption at renotubular level, and elevated serum concentrations of calcitriol, which, in turn, are likely to contribute to increase intestinal phosphate absorption. The parents and sisters of the proband do not present such biochemical and clinical alterations, except for the elder sister. She is heterozygous for the Y322X mutation and carries a developmental anomaly, i.e., the lack of the distal phalanxes of hands and feet. The absence of this abnormality in the proband and in his father, carrying the same mutation, suggests the involvement of either genetic defects other than Y322X mutation or environmental endocrine disrupters in the determination of this phenotype.

At present, recessive loss-of-function mutations in GALNT3 and FGF23 have been found in patients with
HFTC. As far as GALNT3 is concerned, the disease is caused by homozygous mutations in four families (Topaz et al. 2004; Specktor et al. 2006; Campagnoli et al. 2006; Garringer et al. 2006), whereas patients of three other families are heterozygous for either nonsense and splicesite mutations or missense mutations (Topaz et al. 2004; Ichikawa et al. 2005, 2006). The present report describes for the first time the simultaneous presence of two different nonsense mutations in GALNT3 in the same individual.

Concerning FGF23, three homozygous missense mutations have been found in four families (Benet-Pagès et al. 2005; Larsson et al. 2005; Chefetz et al. 2005; Araya et al. 2006). FGF23, a phosphatonin involved in regulation of circulating phosphate, modulates renal excretion of phosphate (Schiavi and Kumar 2004; Berndt et al. 2005). Interestingly, gain-of-function mutations in FGF23 cause autosomal dominant hypophosphatemic rickets (ADHR; MIM \#193100), a disorder considered the metabolic mirror image of HFTC (ADHR consortium 2000). FGF23 is a secreted protein that is cleaved by subtilisin-like proprotein convertase (SPC) at the consensus site RHTR ${ }^{179}$. The mutations identified in ADHR patients lie within the SPC site, indicating that the cleavage process is essential for phosphate homeostasis (Shimada et al. 2002). HFTC patients carrying mutations in FGF23 have low-normal intact FGF23 levels and elevated (up to 40-fold) C-terminal FGF23 concentrations (Larsson et al. 2005; Chefetz et al. 2005). Recent papers show that patients with mutations in GALNT3 have a similar pattern of serum FGF23 levels (low-normal intact, high C-terminal) (Garringer et al. 2006; 
Ichikawa et al. 2006). The observation that lack of GalNAc transferase 3 perturbs normal level of circulating FGF23, together with the fact that FGF23 protein is $O$-glycosylated (Shimada et al. 2002), suggests that a direct enzyme-substrate relationship may exist between GalNAc transferase 3 and FGF23. This hypothesis has recently been supported by cell-based in vitro experiments showing that GalNAc transferase 3 selectively $O$-glycosylates FGF23 in the SPC consensus sequence (Kato et al. 2006).

In summary, the present study reports two novel nonsense mutations in GALNT3 in a patient with HFTC in an Italian family and enlarges the spectrum of genetic alterations responsible for causing the disease.

Acknowledgments We are grateful to the proband and his family for their participation in this study.

\section{References}

ADHR consortium (2000) Autosomal dominant hypophosphataemic rickets is associated with mutations in FGF23. Nat Genet 26:345-348

Araya K, Fukumoto S, Backenroth R, Takeuchi Y, Nakayama K, Ito N, Yoshii N, Yamazaki Y, Yamashita T, Silver J, Igarashi T, Fujita T (2006) A novel mutation in fibroblast growth factor 23 gene as a cause of tumoral calcinosis. J Clin Endocrinol Metab 90:5523-5527

Benet-Pagès A, Orlik P, Strom TM, Lorenz-Depiereux B (2005) An FGF23 missense mutation causes familial tumoral calcinosis with hyperphosphatemia. Hum Mol Genet 14:385-390

Bennet EP, Hassan H, Clausen H (1996) cDNA cloning and expression of a novel human UDP- $N$-acetyl- $\alpha$-D-galactosamine. J Biol Chem 271:17006-17012

Berndt TJ, Schiavi S, Kumar R (2005) "Phosphatonins" and the regulation of phosphorus homeostasis. Am J Physiol Renal Physiol 289:F1170-F1182

Campagnoli MF, Pucci A, Garelli E, Carando A, Defilippi C, Lala R, Ingrosso G, Dianzani I, Forni M, Ramenghi U (2006) Familial tumoral calcinosis and testicular microlithiasis associated with a new mutation of GALNT3 in a white family. J Clin Pathol 59:440-442

Chefetz I, Heller R, Galli-Tsinopoulou A, Richard G, Wollnik B, Indelman M, Koerber F, Topaz O, Bergman R, Sprecher E, Schoenau E (2005) A novel homozygous missense mutation in FGF23 causes familial tumoral calcinosis associated with disseminated visceral calcification. Hum Genet 118:261-266

Frishberg Y, Topaz O, Bergman R, Behar D, Fisher D, Gordon D, Richard G, Sprecher E (2005) Identification of a recurrent mutation in GALNT3 demonstrates that hyperostosis-hyperphosphatemia syndrome and familial tumoral calcinosis are allelic disorders. J Mol Med 83:33-38
Garringer HJ, Fisher C, Larsson TE, Davis SI, Koller DL, Cullen MJ, Draman MS, Conlon N, Jain A, Fedarko NS, Dasgupta B, White KE (2006) The role of mutant GalNAc transferase 3 (GALNT3) in regulating serum intact FGF23 and MEPE in heritable tumoral calcinosis. J Clin Endocrinol Metab 91:4037-4042

Ichikawa S, Lyles KW, Econs MJ (2005) A novel GALNT3 mutation in a pseudoautosomal dominant form of tumoral calcinosis: evidence that the disorder is autosomal recessive. J Clin Endocrinol Metab 90:2420-2423

Ichikawa S, Imel EA, Sorenson AH, Severe R, Knudson P, Harris GJ, Shaker JL, Econs MJ (2006) Tumoral calcinosis presenting with eyelid calcifications due to novel missense mutations in the glycosyl transferase domain of the GALNT3 gene. J Clin Endocrinol Metab 91:4472-4475

Kato K, Jeanneau C, Tarp MA, Benet-Pagès A, Lorenz-Depiereux B, Bennett EP, Mandel U, Strom TM, Clausen H (2006) Polypeptide GalNAc-transferase T3 and familial tumoral calcinosis. Secretion of fibroblast growth factor 23 requires $O$-glycosylation. J Biol Chem 281:18370-18377

Larsson T, Yu X, Davis SI, Draman MS, Mooney SD, Cullen MJ, White KE (2005) A novel recessive mutation in fibroblast growth factor-23 ( FGF23) causes familial tumoral calcinosis. J Clin Endocrinol Metab 90:2424-2427

Metzker A, Eisenstein B, Oren J, Samuel R (1988) Tumoral calcinosis revisited-common and uncommon features Report of ten cases and review. Eur J Pediatr 147:128-132

Prince MJ, Schaeffer PC, Goldsmith RS, Chausmer AB (1982) Hyperphosphatemic tumoral calcinosis: association with elevation of serum 1,25-dihydroxycholecalciferol concentrations. Ann Intern Med 96:586-591

Schiavi SC, Kumar R (2004) The phosphatonin pathway: new insight in phosphate homeostasis. Kidney Int 65:1-14

Shimada T, Muto T, Urakawa I, Yoneya T, Yamazaki Y, Okawa K, Takeuchi Y, Fujita T, Fukumoto S, Yamashita T (2002) Mutant FGF-23 responsible for autosomal dominant hypophosphatemic rickets is resistant to proteolytic cleavage and causes hypophosphatemia in vivo. Endocrinology 143:3179-3182

Slavin RE, Wen J, Kumar D, Evans E (1993) Familial tumoral calcinosis. A clinical, histopathologic, and ultrastructural study with an analysis of its calcifying process and pathogenesis. Am J Surg Pathol 17:788-802

Specktor P, Cooper JG, Indelman M, Sprecher E (2006) Hyperphosphatemic familial tumoral calcinosis caused by a mutation in GALNT3 in a European kindred. J Hum Genet 51:487-490

Ten Hagen KG, Fritz TA, Tabak LA (2003) All in the family: the UDP-GalNAc:polypeptide $N$-acetylgalactosaminyltransferases. Glycobiology 13:1R-16R

Topaz O, Shurman D, Bergman R, Indelman M, Ratajczak P, Mizrachi M, Khamaysi Z, Behar D, Petronius D, Friedman V, Zelikovic I, Raimer S, Metzker A, Richard G, Sprecher E (2004) Mutations in GALNT3, encoding a protein involved in $O$-linked glycosylation, cause familial tumoral calcinosis. Nat Genet 36:579-581

Walton RJ, Bijvoet OLM (1975) Nomogram for derivation of renal threshold phosphate concentration. Lancet 2:309-310 